\title{
Primary capture of cyclodextrin glycosyltransferase derived from Bacillus cereus by aqueous two phase system.
}

\begin{abstract}
In this works, the polymer-salt aqueous two phase system (ATPS) which is polyethyleneglycol (PEG) with sodium citrate was constructed to purify the enzyme CGTase from fermentation broth. Impacts of parameters such as phase composition, tie-line length (TLL), volume ratio (VR), crude sample loading, $\mathrm{pH}$ and the addition of sodium chloride $(\mathrm{NaCl})$ on the partition behavior of cyclodextrin glycosyltransferase (CGTase) were investigated. The study exhibited that the optimum system for the purification of the enzyme CGTase was achieved on the $19.0 \%$ PEG and $11.5 \%$ citrate system with TLL of $38.89 \%(\mathrm{w} / \mathrm{w})$, VR of 2.0 , with additional $4 \%(\mathrm{w} / \mathrm{w}) \mathrm{NaCl}$ and $20 \%$ crude load at $\mathrm{pH}$ 7.0. CGTase from Bacillus sp. was partially purified by the ATPS up to 16.3 -fold with a yield of $70 \%$.
\end{abstract}

Keyword: Aqueous two phase system; Cyclodextrin glycosyltransferase; Cyclodextrin; Enzyme; Purification. 